\title{
Cheiloscopy in the human identification
}

\begin{abstract}
A significant human identification area is Cheiloscopy referred to the study, recording and classification of the external lining of the lips and the impressions they leave. The objective of this study was to conduct a literature review on the methods applied in Cheiloscopy in human identification through literature from the databases available in the databases belonging to the Virtual Health Library (VHL) - Latin American and Caribbean Health Sciences (LILACS), the Nursing Database (BDENF), Scientific Electronic Library Online (SciELO) using traditional and digital methods. It was found that the literature is still lacking in work in this area. New research is necessary, especially in the development of digital methods. The application of Cheiloscopy may in very, collaborate with Justice in identifying suspects. At the end, the company will get the gain.
\end{abstract}

Keywords: forensic dentistry, lips, cheiloscopy, forensic medicine, human identification
Volume 6 Issue 5 - 2018

Isamara Geandra Cavalcanti Caputo,' Laís Ubaldo Antonio, ${ }^{2}$ Ana Paula do Rego André, ${ }^{3}$ Mariana Gonçalves de Castro, ${ }^{4}$ Letícia Batista Pinto, ${ }^{4}$ Raphaela Duarte da Cunha, ${ }^{4}$ Mônica Santiago Oliveira Amaral Carvalho ${ }^{4}$ 'Association of Dental Surgeons, Paulista Institute for Bioethics and Legal Studies, Univeristy of Ribeirão Preto \& University of São Paulo, Brazil

${ }^{2}$ Postgraduated in Forensic Science, Biology University of Franca, University of São Paulo, Brazil

${ }^{3}$ Speech therapist, Postgraduated in Forensic Science,University of São Paulo, Brazil

${ }^{4}$ Postgraduated in Forensic Science, Paulista Institute for Bioethics and Legal Studies, Brazil

Correspondence: Isamara Geandra Cavalcanti Caputo, Association of Dental Surgeons, Paulista Institute for Bioethics and Legal Studies, Univeristy of Ribeirão Preto \& University of São Paulo, Street: Casemiro de Abreu, 572 Vila Seixas Ribeirão Preto, Brazil, Email isamaracevalcanti@gmail.com

Received: October 06, 2018 | Published: November 16, 2018

\section{Introduction}

One of the most challenging issues that man has been confronted with is human identification. ${ }^{1}$ Identifying identity is a fundamental process in Legal Medicine, both in civil and criminal terms ${ }^{2,3}$ being a prerequisite for the certification of death as well as for personal, social and legal reasons. ${ }^{4,5}$ Dactyloscopy (evaluation of fingerprints), dental records and deoxyribonucleic acid (DNA) are the most common techniques used, allowing the rapid and secure identification process. However, in certain circumstances, related to the crime scene or lack of experienced personnel, these techniques may not be available. Therefore, there is a growing need to apply alternative methods to establish identity, ${ }^{6}$ as is the case of soft tissue identification, an example being queiloscopy. Cheiloscopy is an area of Forensic Dentistry that applies to the study, registration and classification of lip impressions. ${ }^{7}$ Greek word of origin, queiloscopy means examination of the lips, where cheilos=lips and skopein=examination.

Considering, for example, that a labial impression can be left in a crime scene, and provide direct access to the suspect, its analysis is a method that can be used in human identification. ${ }^{8,9}$ The interest in using this technique is scarce for studies on corpses. For this purpose, other techniques provide better post-mortem data. The study of the labial impressions occurs through the analysis of the lines, fissures, wrinkles and striae present in the lip. Its application is advantageous and quite useful when confronting lip impressions left on objects or belongings, such as cups, bowls, cigarette butts, paper napkins or even on cushions or similar used in cases of suffocation. When a lip mark is related to a victim or suspect at a crime scene, it then becomes evidence and has to be analyzed as such. The technique of identification by means of queiloscopy has the necessary criteria to be considered a method of identification, are unique to each individual (uniqueness), do not change throughout life (immutable), there are classification tables of types of labial drawings (classification), is an easy-to-use method (practicability), and after death, as well as the digital pulps, it remains for some time, yet it can be used (perennial). Due to these characteristics, lip printing is a valid medium to be used, especially in criminal investigation. ${ }^{10}$

\section{Methodology}

A bibliographic survey was carried out on the methods used in queiloscopy for the purpose of human identification, where it was decided to systematically search for articles in national and international journals, available in the databases belonging to the Virtual Health Library (VHL) American and Caribbean Health Sciences (LILACS), Nursing Database (BDENF), Scientific Electronic Library Online (SCIELO) and PubMed. The descriptors used were: lips, forensic dentistry, forensic medicine, human identification, cheiloscopy.

\section{Bibliographical review}

\section{Composition of the Lips}

The lips are two mobile, highly sensitive mucocutaneous folds composed of skin, muscles, sebaceous glands and mucous membranes, forming the anterior border of the oral cavity6. Anatomically, the labial structure is formed by the upper lip and the lower lip, joined by the labial commissaries. ${ }^{8,10,11}$ The upper lip extends from the base of the nasal septum to the commissure and in its middle zone and has a depression called the nasolabial sulcus. In the lower lip, the midline of the mentolabial sulcus, limited between the cutaneous lip and the mentum, is found. ${ }^{12}$ On the lips there are two classes of coating: one cutaneous and another mucosa. In the place of union of both, there is a wavy and whitish line, called the lip margin, especially visible in individuals with black skin. ${ }^{13}$ The anatomical area known as vermilion lip area is the important area for the study of lip impressions, since 
it corresponds to the area of the mucosa with a thin epithelium and that presents a thin layer of keratin, well vascularized and devoid of dermal appendages with few glands sebaceous that are covered by lines and grooves that determine the labial pattern. ${ }^{14}$ Several criteria are considered in the identification process, such as the thickness of the lips and the shape of the labial commissures. ${ }^{6,9-11,13}$

\section{Classification of lip impressions}

Throughout history, various classifications of lip impressions have emerged, among them Martin Santos's classification, Suzuki's and Tsuchihashi's classification (the most widely used), Renaud's classification, José Maria Dominguez's classification, the classification of Afchar Bayat and classification of Oviedo and Meira. ${ }^{6,7}$

\section{Classification of martın Santos}

Martin Santos suggested the first classification of lip impressions in the year 1967.,15,16 in which he divided the labial grooves into two groups: simple and compound. The first is determined only by one form and the second, when they are formed by two or more distinct forms. ${ }^{6,10,17}$ When used, this classification refers to an alphanumeric code identifying the corresponding quadrant (Table 1).

Table I Adaptation of the classification of martin santos ${ }^{6,10,17}$

\begin{tabular}{ll}
\hline Simple & Composite \\
\hline Straight grooves (R-I) & Bifurcated (B-5) \\
Curved grooves (C-2) & Trifurcated grooves (T-6) \\
Angular grooves (A-3) & Anomalous (Na-7) \\
Sinusoidal grooves (S-4) & \\
\hline
\end{tabular}

\section{Classification of suzuki and tsuchihashi}

Suzuki and Tsuchihashi developed a new classification in the year $1970,{ }^{1,6,18,19}$ based on the shape and the path of the labial impression grooves using two axes, one vertical and one horizontal (Table 2). ${ }^{10}$ This is the most usual classification because of its clear description of the lip groove patterns, making its interpretation easier. ${ }^{4,10}$ In this classification the lips are divided into four quadrants, the upper quadrants being called $\mathrm{Y}$ and $\mathrm{Y}$ ' and the lower quadrants denominated by $\mathrm{X}$ and $\mathrm{X}$ ', perpendicular to the medial sagittal plane, which divides them into right and left. Each quadrant is divided into four sections, which allows a better reading and observation of the labial impression (Figure 1) ${ }^{13} \mathrm{~A}$ variation is proposed in the male versus female pattern that may help in the context of personal identification and gender determination. Through a study it was verified that the gender of the individual was determined according to the Suzuki and Tsuchihashi classification (Table 3). ${ }^{1,5,11,20}$

Table 2 Adaptation of Suzuki and tsuchiha classification $6,10,13$

\begin{tabular}{ll}
\hline Type & Type of grooves \\
\hline I & Complete Vertical Grooves \\
I & Incomplete Vertical Grooves \\
II & Branched or bifurcated grooves \\
III & Crossed Grooves \\
IV & Reticulated Grooves \\
V & Grooves of another pattern
\end{tabular}
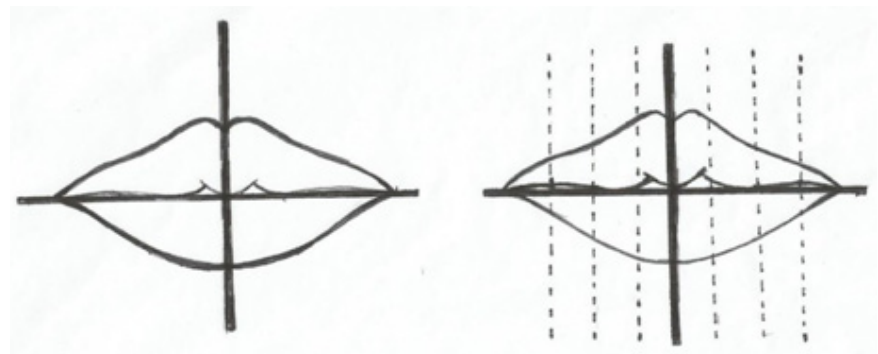

Figure I Suzuki and tsuchihashi scheme. ${ }^{13}$

Table 3 Results obtained in the study regarding the determination of gender $1,5,14,20$

\begin{tabular}{lll}
\hline Type I, I 'and II & Dominant pattern & Female \\
Type III and IV & Dominant pattern & Male \\
Type V & Variable pattern & Male \\
\hline
\end{tabular}

\section{Classification of renaud}

Considered as the most complete classification, ${ }^{6,17}$ it consists of dividing the upper and lower lip into the right and left sides and into four quadrants. The upper right lip is designated by the letter " $D$ ", the upper left lip by the letter "d". The lower right lip by the letter "E" and the lower left lip by the letter "e" (Figure 2). ${ }^{6,10}$

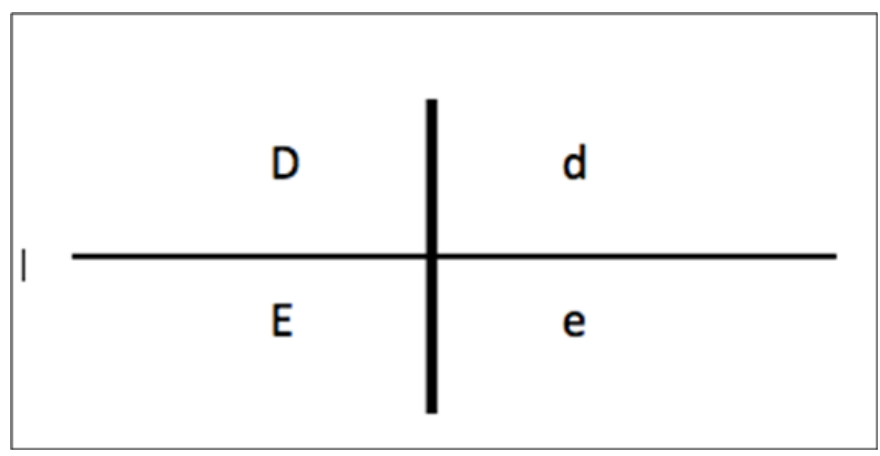

Figure 2 Division of the upper and lower lip according to the renaud classification. ${ }^{6,10}$

Renaud described ten types of lipstick, using the first to tenth letters of the alphabet, with lower case letters designating the lower lip and upper case upper lip (Table 4 \& Figure 3).

Table 4 Renaud classification ${ }^{6,10}$

\begin{tabular}{ll}
\hline Type & Type of groove \\
\hline $\mathrm{A} / \mathrm{a}$ & Complete vertical grooves \\
$\mathrm{B} / \mathrm{b}$ & Incomplete vertical grooves \\
$\mathrm{C} / \mathrm{C}$ & Complete bifurcated grooves \\
$\mathrm{D} / \mathrm{d}$ & Incomplete bifurcated grooves \\
$\mathrm{E} / \mathrm{e}$ & Complete branched grooves \\
$\mathrm{F} / \mathrm{f}$ & Incomplete branched grooves \\
$\mathrm{G} / \mathrm{g}$ & Reticulated grooves \\
$\mathrm{H} / \mathrm{h}$ & Grooves in $\mathrm{X}$ \\
$\mathrm{I} / \mathrm{i}$ & Horizontal grooves \\
$\mathrm{J} / \mathrm{j}$ & Other shapes (ellipse, triangle, oval or with microscopes) \\
\hline
\end{tabular}




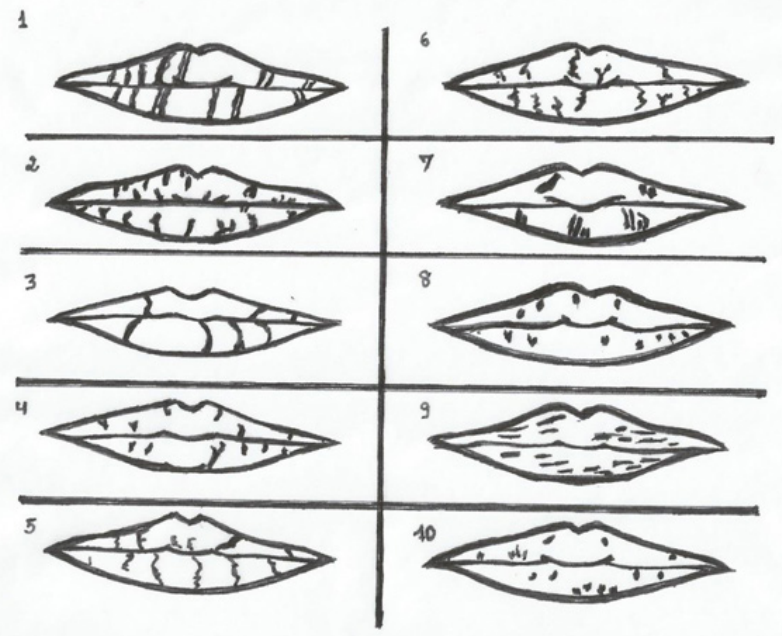

Figure 3 Renaud classification scheme..$^{6,10}$

\section{Classification of josé maria dominguez}

Divergent to the classification of Suzuki and Tsuchihashi, this classification was suggested in the year 1975, and maintains all types of patterns, except those of type II. The bifurcations that are produced up to the upper lip and below the lower lip are called as type II, and as type II 'the lines that in the same lip are bifurcated above and below. ${ }^{10}$

\section{Classification of afchar-bayat}

Dating back to 1979, the classification of Afchar-bayat is based on the classification of Suzuki and Tsuchihashi, however it describes the lines and grooves present in the lips in a different way6 and is described in Table 5.

Table 5 Classification of afchar-bayat ${ }^{6}$

\begin{tabular}{ll}
\hline Type & Type of grooves \\
\hline Al & Complete vertical grooves \\
A2 & Incomplete vertical grooves \\
BI & Straight branched grooves \\
B2 & Angular branched grooves \\
C & Converging grooves \\
D & Reticulated grooves \\
E & Grooves of another shape \\
\hline
\end{tabular}

\section{Classification of oviedo and Meira}

Oviedo and Meira suggested in the year 1988 a classification that is also based on the classification of Suzuki and Tsuchihashi. However, it emphasizes the depth of the grooves, dividing them into superficial and deep (Table 6). ${ }^{10}$

Table 6 Classification of Oviedo and meira (Adapted from Pereira ${ }^{10}$ )

\begin{tabular}{|c|c|c|}
\hline Transversal grooves in the lips & Grooves with lobes & $\begin{array}{l}\text { Grooves in bouffled shapes } \\
\text { with origin in internal ridge }\end{array}$ \\
\hline Total & Longitudinal partial or total grooves & \\
\hline External partial & Convergent or divergent to labial comissure & \\
\hline \multirow[t]{2}{*}{ Internal partial } & Superficial grooves in cross linked & \\
\hline & Grooves in cross linked & \\
\hline
\end{tabular}

The identification of a living individual or corpse is of immeasurable importance from the medical, legal and social point of view, becoming more and more constant the situations in which it is necessary. Because it is a simple, non-invasive technique that is easy to access and does not require a very complex instrument, queiloscopy is a technique that can be used to aid human identification processes, but it is still rarely used. Cheiloscopy is an area with potential for evolution that, together with other available techniques, becomes even more useful for human identification.

\section{Conclusion}

It was verified that the literature is still lacking in works in this area. New research is needed, especially in the development of digital methods. The application of Queiloscopia can, in many cases, collaborate with the Justice, in the identification of suspects. In the end, society will get the gain.

\section{Acknowledgements}

None

\section{Conflict of interest}

The author declares that there is no conflict of interest.

\section{References}

1. Malik R, Goel S. Cheiloscopy: A Deterministic Aid for Forensic Sex Determination. Journal of Indian Academy of Oral Medicine and Radiology. 2011;23(1):17-19.

2. Woelfert A. Introdução à Medicina Legal. Canoas. Editora Da Ulbra. 2003.

3. Reddy L. Lip Prints: An Overview in Forensic Dentistry. Journal of Advanced Dental Research. 2011;2(1):17-20.

4. Gondivkar SM, Indurkar A, Degwekar S, et al. Cheiloscopy for Sex Determination. Journal of Forensic Dental Sciences. 2009;1(2):56-60.

5. Narang R, Arora P, Randhawa K. Cheiloscopy as an Aid to Forensic Methodology. Indian Journal of Comprehensive Dental Care. 2011;1(1):57-60.

6. Caldas I, Magalhães T, A fonso A. Establishing Identity Using Cheiloscopy and Palatoscopy. Forensic Science International. 2007;165(1):1-9.

7. Costa V, Caldas I. Morphologic Patterns of Lip Prints in a Portuguese Population: A Preliminary Analysis. Journal of Forensic Sciences. 2012;57(5):1318-1322.

8. Utsuno H, Kanoh T, Tadokoro O, et al. Preliminary Study of Post Mortem Identification Using Lip Prints. Forensic Science International. 2005;149(2-3):129-132. 
9. Saxena S, Sharma P, Gupta N. Experimental Studies of Forensic Odontology to Aid in the Identification Process. Journal of Forensic Dental Sciences. 2010;2(2):69-76.

10. Pereira C. Medicina Dentária Forense. Lisboa, Lidel. 2012.

11. Sharma P, Saxena S, Rathod V. Comparative Reliability of Cheiloscopy and Palatoscopy in Human Identification. Indian Journal of Dental Research. 2009a;20(4):453-457.

12. Figini AR L, Silva JR L, Jobim LF, et al. Identificação Humana. Campinas. Mellennium. 2003.

13. Pueyo V, Garrido B, Sánchez J. Odontológia Legal Y Forense. Barcelona, Masson. 1994.

14. Sharma P, Saxena S, Rathod V. Cheiloscopy: The Study of Lip Prints in Sex Identification. Journal of Forensic Dental Sciences. 2009b;1(1):24-27.
15. Saraswathi T, Mishra G, Ranganathan K. Study of Lip Prints. Journal of Forensic Dental Sciences. 2009;1(1):28-31.

16. Chauhan S, Arora A, Kaul A. A Survey of Emerging Biometric Modalities. Procedia Computer Science. 2010;2:213-218.

17. Domiaty M, Al-Gaidi AS, Elayat AA, et al. Morphological Patterns Of Lip Prints In Saudi Arabia At Almadinah Almonawarah Province. Forensic Science International. 2010;200(1):179 -179.

18. Prabhu R, Dinkar A, Prabhu V. Collection Of Lip Prints As A Forensic Evidence At The Crime Scene - An Insight. Journal of Oral Health Research. 2010;1(4):129-135.

19. Narang R, Arora P, Randhawa K. Cheiloscopy as an Aid to Forensic Methodology. Indian Journal of Comprehensive Dental Care. 2011;1(1):57-60.

20. Vahanwala S, Nayak C, Pagare S. Study of Lip-Prints as Aid for Sex Determination. Medico-Legal Update. 2005;5(3):93-98. 